\title{
The identity of Pseudopsila, description of a new subgenus of Psila, and redefinition of Psila sensu lato (Diptera: Psilidae)
}

\author{
Matthias BUCK and Stephen A. MARSHALL \\ Department of Environmental Biology, University of Guelph, Guelph, Ontario N1G 2W1, Canada; e-mail: mbuck@uoguelph.ca
}

Key words. Psila, Xenopsila, Pseudopsila, Psilidae, phylogeny, redefinition, subgenera, key, new synonymy, new subgenus, New World, morphology, male genitalia, egg

\begin{abstract}
The type species of Pseudopsila Johnson, P. fallax (Loew), and two related species are found to belong in Psila s. str., and Pseudopsila is thus synonymized with Psila Meigen. The remaining species formerly included in Pseudopsila form a monophyletic group here described as Xenopsila Buck subgen. n. [i.e., Psila (Xenopsila) collaris Loew comb. n., P. (X.) bivittata Loew comb. n., $P$. (X.) lateralis Loew comb. n., $P .(X$.$) arbustorum Shatalkin comb. n., P .(X$.$) nemoralis Shatalkin comb. n., P$. $(X$.) tetrachaeta (Shatalkin) comb. n., P. (X.) maculipennis (Frey) comb. n., P. (X.) nigricollis (Frey) comb. n., P. (X.) nigrohumera (Wang \& Yang) comb. n.]. A key to the Nearctic species of Xenopsila and the Psila fallax-group is provided. The placement of Xenopsila in Psila s. 1. is confirmed by newly recognised synapomorphies of the egg stage. The somewhat questionable monophyly of Psila s. 1. is confirmed based on these new synapomorphies, thereby slightly expanding its taxonomic limits to also include Asiopsila Shatalkin. The morphology of the male genitalia of Xenopsila is discussed in detail, clarifying confused homologies and character polarities in the hypandrial complex. Evolutionary trends in the development of the hypandrium in the subfamily Psilinae are discussed.
\end{abstract}

\section{INTRODUCTION}

The genus Pseudopsila Johnson, 1920 was originally erected for Psila-like flies with an elongated first flagellomere (Figs 1, 3) a character interpreted by some (Johnson, 1920; Capelle, 1953) as evidence of a close relationship with Loxocera Meigen, 1803. More recently Pseudopsila has been considered a subgenus or synonym of Psila Meigen, 1803 (e.g., Shewell, 1965; Cogan, 1977; Steyskal, 1987; Iwasa, 1991, 1998). Shatalkin (1986) first used male genitalic characters to define Pseudopsila. Based on these characters he later re-instated Pseudopsila as a genus separate from Psila s. 1., considering it the most primitive group within the subfamily Psilinae (Shatalkin, 1998b). Currently, six Nearctic (Johnson, 1920, Shewell, 1965), three Palaearctic (Iwasa, 1998; Shatalkin, 1998b) and two Oriental species (Frey, 1955) are included in this group.

Previous authors did not realise that Pseudopsila is an artificial group. In the present paper we clarify the relationships of the type species of Pseudopsila, and synonymize this genus with Psila s. str. For the majority of species previously placed in Pseudopsila we describe the new subgenus Xenopsila Buck subgen. n., which agrees with Shatalkin's $(1986,1998 b)$ definition of Pseudopsila based on male genitalic characters. The phylogenetic relationships of Xenopsila are reviewed based on egg morphology and male genitalic characters. Xenopsila is treated as a subgenus of Psila s. 1., rejecting Shatalkin's (1998b) exclusion of this group from Psila s. 1. The confused homologies and character polarities of the peculiar male genitalia of Psila (Xenopsila) are discussed in detail and viewed in the context of apparent evolutionary trends in the subfamily Psilinae. The new findings on egg morphology lead to a slightly revised definition of the genus
Psila, whose monophyly is thereby clearly demonstrated for the first time.

\section{MATERIALS AND METHODS}

\section{Preparation methods}

Male and female abdomens were cleared in hot $10 \% \mathrm{KOH}$, neutralized in glacial acetic acid and stored in glycerine. All eggs described in this paper were obtained by dissection from gravid females (museum specimens).

\section{Photography}

Photographs of museum specimens were taken with a Microptics Digital Lab XLT imaging system using a Canon EOS 1 Ds camera and Microptics ML-1000 flash fibre optic illumination system. Each image was assembled from a series of photographs (with different focal planes) using the computer freeware CombineZ, version 4.6 (Hadley, 2004).

\section{Terminology}

The morphological terminology follows McAlpine (1981) except for certain terms pertaining to the phallic complex, which follow Andersson (1977). For a discussion of the terminology related to the phallic complex in Psilidae see Buck \& Marshall (2006).

\section{Acronyms of depositories}

CNCI - Canadian National Collection of Insects, Ottawa, Ontario, Canada; DEBU - Department of Environmental Biology, University of Guelph, Guelph, Ontario, Canada; ZSMC Zoologische Staatssammlungen, München, Germany.

\section{TAXONOMY}

\section{Genus Psila Meigen, 1803}

\section{Subgenus Psila Meigen, 1803}

Psila Meigen, 1803: 278. Type species: Musca fimetaria Linnaeus, 1761: 458 (designated by Westwood, 1840: 146).

Peletophila Hagenbach, 1822: 48 (objective synonym of Psila). Psilomyia Latreille, 1829: 525 (unjustified new name for Psila). 

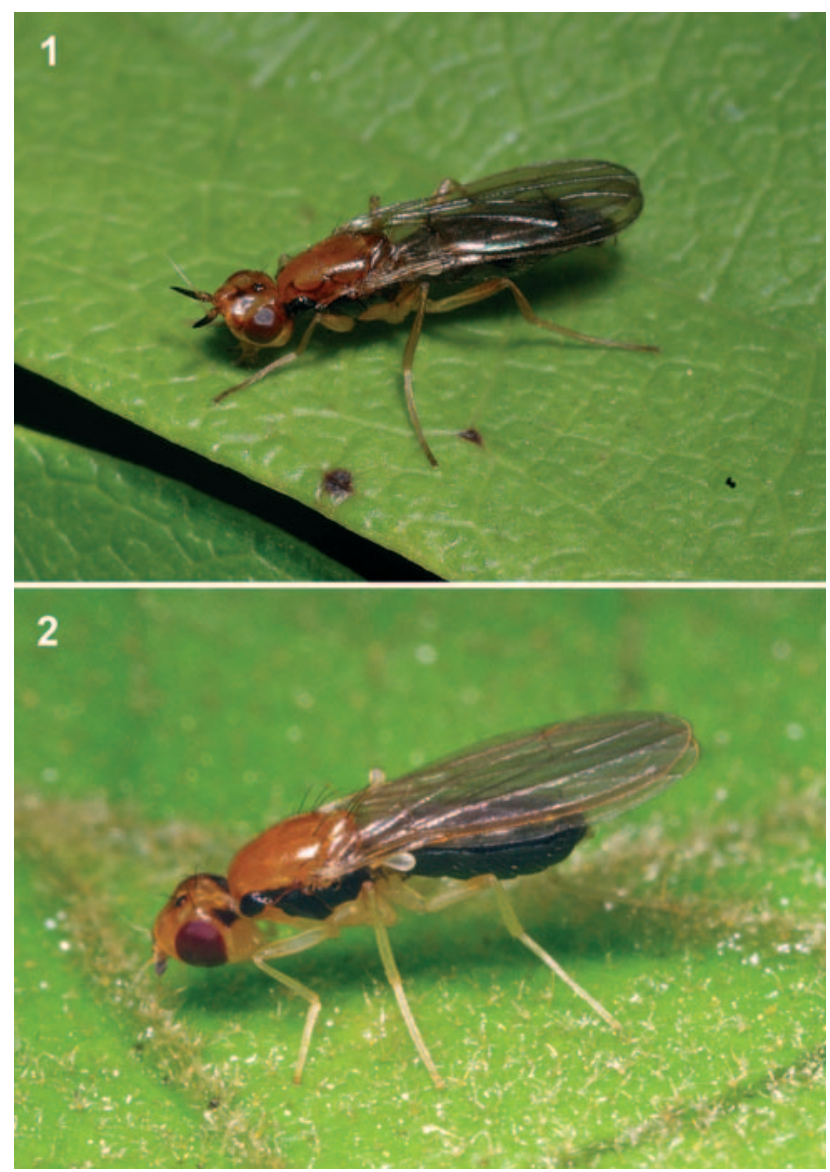

Figs 1-2. Adult Psila: $1-P$. (Psila) angustata, female (Canada, Ontario); 2 - P. (Xenopsila) lateralis, male (USA, Virginia).

Oblicia Robineau-Desvoidy, 1830: 620 (objective synonym of Psila).

Chamaepsila Hendel, 1917: 37. Type species: Musca rosae Fabricius, 1794: 356 (preocc.) $[=$ Chamaepsila hennigi Thompson \& Pont, 1994: 161].

Tetrapsila Frey, 1925: 48. Type species: Psila obscuritarsis Loew, 1856: 54

Pseudopsila Johnson, 1920: 17. Type species: Loxocera fallax Loew, 1869: 185; syn. n.

Taxonomic status of Pseudopsila. When Johnson (1920) described Pseudopsila he mentioned only one character to distinguish his new genus from Psila: the moderately elongated first flagellomere (Figs 3, 5, 6). Based on this character Johnson (1. c.) included five Nearctic species in Pseudopsila, four of which had previously been treated as Psila. Later, more species from the eastern Palaearctic (Shatalkin, 1983, 1986, 1998b), Oriental (Frey, 1955) and Nearctic (Shewell, 1965) were added by other authors. Shewell (1965) expanded the concept of Pseudopsila by transferring Psila lateralis Loew, 1860 (with short first flagellomere, Fig. 4) to the group. The Nearctic species of Pseudopsila are only superficially similar, and can be divided into two distinct groups with very different male genitalia. The first group, here called the $P$. fallax-group, includes the type species of Pseudopsila, P. fallax Loew, 1869 (Fig. 3), plus two other species [P. angustata Cresson, 1919 (Fig. 1), $P$. perpolita Johnson, 1920]. The other group consists of $P$. collaris Loew, 1869 (Fig. 6), P. bivittata Loew, 1869 (Fig. 5), and P. lateralis (Figs 2, 4). These three species are part of a larger group that includes all the Old World species of Pseudopsila.

Remarkably, the $P$. fallax-group possesses genitalia that are very similar to the type species of Psila (Figs 8, 9). The elongate first flagellomere is in fact the only character distinguishing the $P$. fallax-group from other Psila s. str. Antennal length is highly homoplastic in the Psilinae, and elongated first flagellomeres occur in a wide variety of taxa such as Xenopsila subgen. n. [excl. $P$. (X.) lateralis], in at least one species of Psila (Freyopsila Shatalkin, 1986), in Psila (Asiopsila Shatalkin, 1998) (all species), and in Loxocera s. 1. (the sister group of Psila s. 1.). Due to the high degree of homoplasy of antennal length within Psila and significant male genitalic differences within the $P$. fallax-group (see below) it is presently unclear whether this group is monophyletic. Even if its monophyly were demonstrated its elevation to subgenus rank (under the available name Pseudopsila) would very likely result in a paraphyletic Psila s. str. We therefore propose the synonymy of Pseudopsila with Psila s. str.

Unlike the $P$. fallax-group, species of the second group ( $P$. collaris and related species) have male genitalia that are very different from Psila s. str. (Figs 11, 12). They share several distinct synapomorphies, proving the monophyly of this group: e.g., a reduced hypandrial plate, hypandrial arms that are fused to the phallapodemic sclerite, elongate, apically notched postgonites, and an elongate, apically bifid phallus. Shatalkin (1986) was first in recognising the unique genitalic features of this group. Later, he based his definition of Pseudopsila entirely on genitalic characters (Shatalkin, 1998b), thereby justifying the placement of three species with short first flagellomeres (incl. P. lateralis) in this group. Unfortunately, Shatalkin did not have the opportunity to examine the type species $P$. fallax (or the related $P$. angustata and $P$. perpolita), which led him to believe that Pseudopsila was the correct name for the group he was dealing with. In fact, the group of species around $P$. collaris represents a new subgenus, which is here described as Xenopsila Buck subgen. $\mathrm{n}$.

Taxonomic status of the Psila fallax-group. Whether the three species here transferred to Psila s. str. form a monophyletic group cannot be established without reviewing the whole subgenus. Psila fallax and $P$. angustata are undoubtedly sister species because they share a very peculiar autapomorphy that has not been found in other Psila: The phallus bears a pair of small fimbriate, posterior appendages (Fig. 9: ap) about halfway between its base and apex. These appendages are absent in P. perpolita, whose male genitalia differ quite significantly in other respects as well. In this species the hypandrial arms, postgonites and phallapodemic sclerite are fused into a single sclerite, the postgonites are differently shaped, and the hypandrial plate is shortened and hardly overlapping 

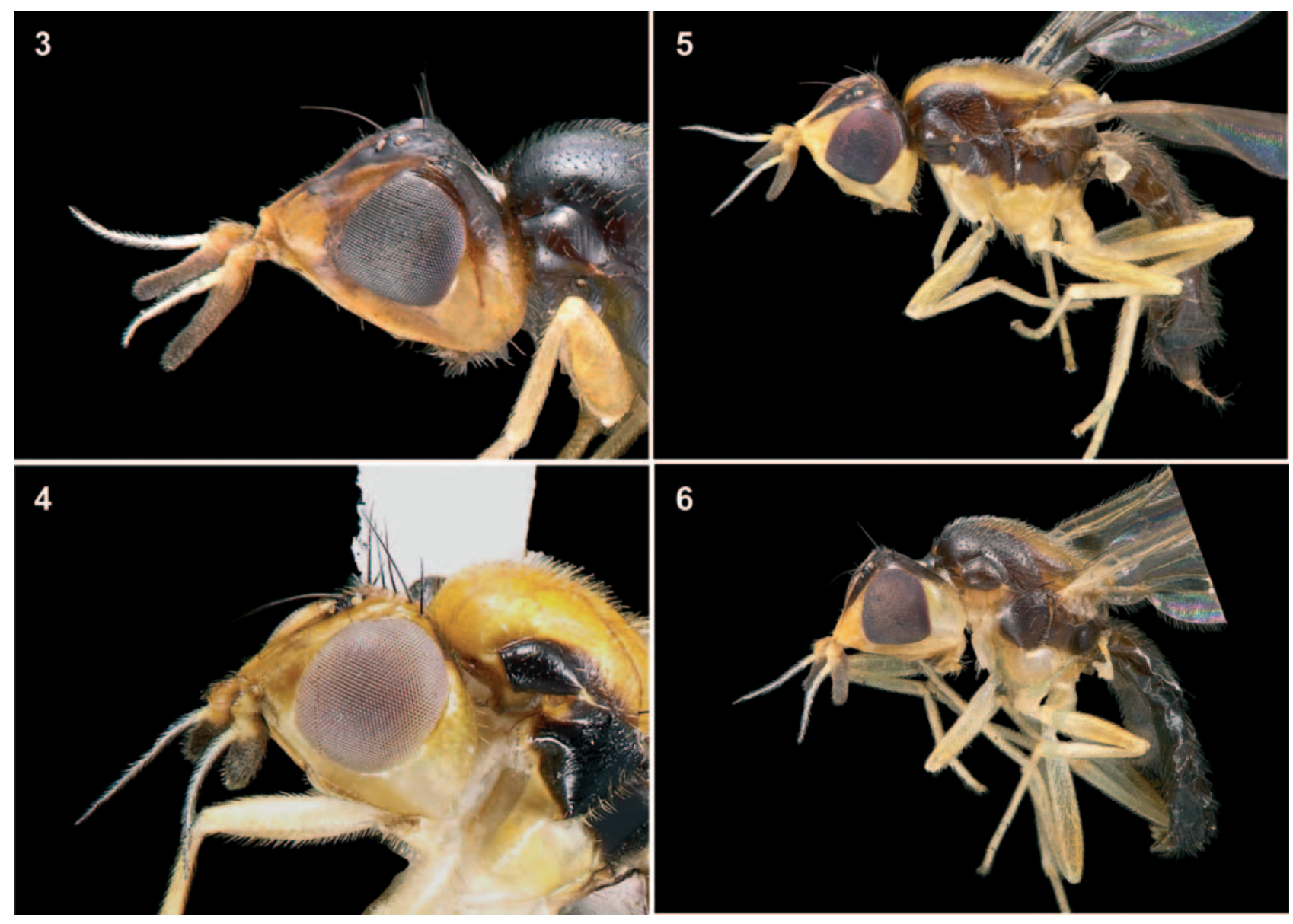

Figs 3-6. Adult Psila: 3 - P. (Psila) fallax, head (Canada, New Brunswick); 4 - P. (Xenopsila) lateralis, head (USA, Texas); 5 P. (Xenopsila) bivittata, female (Canada, Quebec); 6 - P. (Xenopsila) collaris, male (Canada, Ontario).

with the phallapodemic sclerite. Apart from the lengthened first flagellomere and white arista there are no other apomorphic characters that link $P$. perpolita to $P$. fallax/P. angustata. Due to the high degree of homoplasy in Psila s. 1. antennal morphology alone can only provide weak support for the monophyly of these three species.

Diagnosis of Psila s. str. After transferring the $P$. fallax-group back to Psila s. str. the diagnosis for the subgenus needs to be modified in order to distinguish it from Xenopsila subgen. $\mathrm{n}$. (diagnosis based mainly on Nearctic species; see list of species examined below): Outer vertical bristles simple or duplicated, postvertical bristles present or absent. First flagellomere short to moderately elongated (1.5-4.0× as long as high), arista usually somewhat darkened, sometimes conspicuously white (Fig. 3). Mesonotum with 1-4 (1-2 in Nearctic species) pairs of dorsocentral bristles. Scutellum usually with two, rarely with four bristles. Male sternite 6 rectangular (Fig. 7), neither shortened nor posteriorly emarginate. Pregenital sclerite (= tergite 7 ?) reduced to a small median plate (Fig. 8: pgs), sometimes fused to epandrium or absent. Hypandrial arms usually separated from hypandrial plate (Fig. 9: ha, hp); only in a few species (e.g., P. dimidiata Loew, 1869) connected to the hypandrial plate. In $P$. perpolita hypandrial arms, postgonites and phallapodemic plate fused into a single sclerite. Phallapodeme usually absent (e.g., Fig. 8); in a few species large and laterally compressed (e.g., P. dimidiata). Phallapodemic sclerite developed as a horizontal plate (Fig. 8, 9: ps), juxtaposed to hypandrial plate and membranously connected to it along margins; phallic pouch usually well developed, sometimes more or less shortened. Phallus usually short (Fig. 9: ph), not extending into phallic pouch. Postgonites usually strongly sclerotized and at least in part black, usually short and rounded (Figs 8, 9: pg), inserted apically on phallapodemic arms.

\section{Species examined (Psila fallax-group)}

The species of the P. fallax-group are keyed below together with the Nearctic species of Xenopsila subgen. $\mathrm{n}$.

\section{Psila (P.) angustata Cresson, 1919}

(Fig. 1)

Psila angustata Cresson, 1919: 193.

Material examined. Canada, Ontario: $3 \hat{\jmath}, 5 \uparrow$, Fergus, Port Franks, Walpole Island. USA, North Carolina: 19 (tentatively identified as $P$. angustata), Cullowhee (all DEBU).

\section{Psila (P.) fallax (Loew, 1869)}

(Figs 3, 7-9)

Loxocera fallax Loew, 1869: 185.

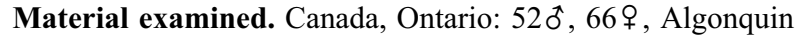
Provincial Park, Belwood, Bruce Peninsula National Park, 

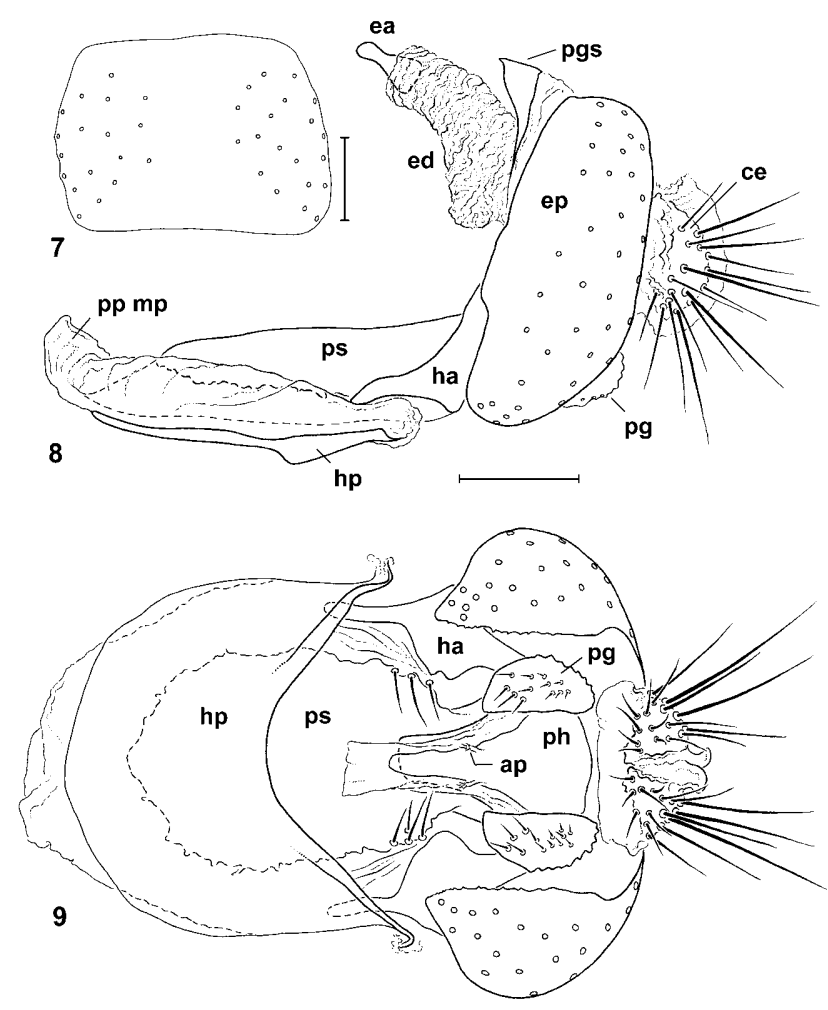

Figs 7-9. Male genitalia and sternite 6 of Psila (P.) fallax (Canada, Ontario): 7 - sternite 6 (posterior margin at bottom), 8 - genitalia, lateral view; 9 - genitalia, ventral view. Scale 0.1 $\mathrm{mm}$. ap - appendages of phallus, ce - cercus, ea - ejaculatory apodeme, ed - ejaculatory duct, ep - epandrium, ha - hypandrial arm, hp - hypandrial plate, pg - postgonite, $\mathrm{ph}$ - phallus, pp mp - membranous portion of phallic pouch, ps - phallapodemic sclerite, pgs - pregenital sclerite.

Crane River, Dorset, Guelph, Hamilton, Hepworth, Hilton Township, Johnstown, Killbear Provincial Park, Presqu'ile Provincial Park, Rosseau, Sault Ste. Marie, 12 km NNE Searchmont, Tobermory, Windsor. New Brunswick: $10,1 \%$, St. Andrews. Nova Scotia: 1 , Cape Breton Highlands National Park (all DEBU).

\section{Psila (P.) perpolita (Johnson, 1920)}

Pseudopsila perpolita Johnson, 1920: 18.

Material examined. Canada, Saskatchewan: 19 , Hudson Bay (CNCI). Ontario: 10 $\hat{0}, 26 \%$, Algonquin Provincial Park, Galloway Lake nr. Ranger Lake $47^{\circ} 13.1^{\prime} \mathrm{N} 83^{\circ} 54.2^{\prime} \mathrm{W}$, Guelph, Hilton Township, Kanata, Port Franks, Sault Ste. Marie, 6 km ENE Searchmont, Dupont Rd. nr. Searchmont $47^{\circ} 4.5^{\prime} \mathrm{N}$ $83^{\circ} 49.2^{\prime} \mathrm{W}$. Quebec: $1 \delta^{\prime}$, Gatineau Co., Masham Township. New Brunswick: 4ð, 5 $q$, Mt. Carleton Provincial Park. Nova Scotia: 2 \% , Cape Breton Highlands National Park (all DEBU).

\section{Other Psila s. str. species examined (excluding Psila fallax-group)}

Nearctic species: $P$. dimidiata Loew, 1869, P. levis Loew, 1869, P. microcera Melander, 1920, P. persimilis Wakerley, 1959 (first record of this Palaearctic species from the New World based on 84 specimens from numerous localities in southern Ontario), $P$. hennigi (Thompson \& Pont, 1994) [= Musca rosae Fabricius, 1794, preocc.], P. sternalis Loew, 1869, and P. washing-
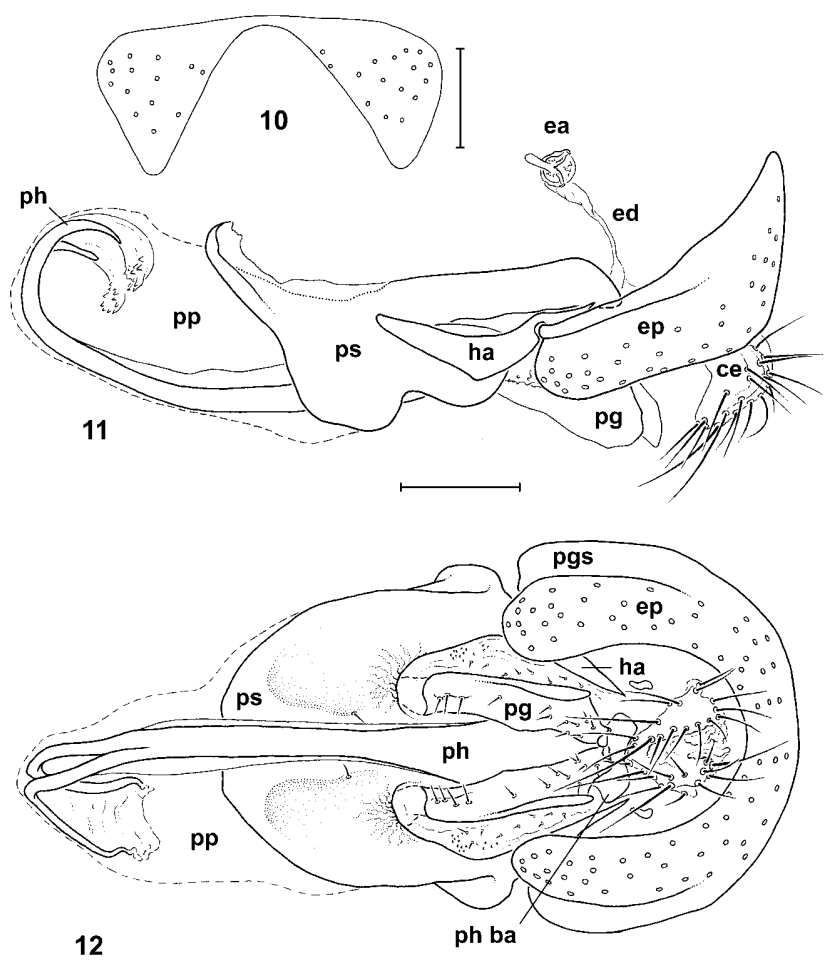

Figs 10-12. Male genitalia and sternite 6 of Psila (Xenopsila): $10-P .(X$.) collaris (Canada, Ontario), sternite 6 (posterior margin at bottom); $P$. (X.) lateralis (Canada, Ontario), male genitalia: 11 - lateral view, 12 - ventral view. Scale 0.1 $\mathrm{mm}$. ce - cercus, ea - ejaculatory apodeme, ed - ejaculatory duct, ep - epandrium, ha - hypandrial arm, pg - postgonite, ph - phallus, ph ba - base of phallus, pp - phallic pouch, ps - phallapodemic sclerite, pgs - pregenital sclerite.

tona Melander, 1920 (all DEBU). Palaearctic species: Psila fimetaria (Linnaeus, 1761) [type species of Psila] (Germany, Bayern: 3 $\delta, 3$ \&, ZSMC).

\section{Subgenus Xenopsila Buck subgen. $\mathbf{n}$.}

Type species. Psila collaris Loew, 1869.

Diagnosis. The following diagnosis is mostly based on Nearctic species (Old World species were not available for examination): Outer vertical bristles simple, never duplicated, postvertical bristles present. First flagellomere short to moderately elongated (2.0-4.0 $\times$ as long as high), arista conspicuously white (Figs 4-6). Mesonotum with one pair of dorsocentral bristles (Note: Shatalkin (1986) erroneously stated that all Nearctic species of "Pseudopsila" possess two pairs of dorsocentrals. The only species with two dorsocentrals, $P$. perpolita, is part of the fallaxgroup). Scutellum with four or two bristles. Male sternite 6 transverse (Fig. 10), with triangular, posteromedial emargination that (almost) divides the sternite into two triangular halves. Pregenital sclerite obliterated medially, distinct laterally, completely fused to epandrium (Fig. 12: pgs). Hypandrial plate completely reduced in conjunction with shortening of sternite 6; hypandrial arms anteriorly fused to phallapodemic sclerite (Fig. 11, 12: ha, ps). Phallic pouch delicate and completely membranous (Fig. 11: $\mathrm{pp}$ ), accommodating recurved apical portion of 
phallus at rest. Ventral surface of phallapodemic sclerite (Fig. 12: ps) openly exposed (visible in undissected specimens) due to shortening of sternite 6 and loss of hypandrial plate, anteriorly with a trough-like, longitudinal, medial groove, receiving distal portion of phallus; groove bordered by a pair of large, rounded elevations. Phallus elongated (Fig. 12: ph); apical third longitudinally divided into two membranously connected strands; apex shallowly incised. Postgonites moderately sclerotized (Fig. 12: pg), light brown, elongated with emarginate apex, inserted in an unusually anterior position at very base of phallapodemic arms.

Etymology. The name Xenopsila is derived from the Greek word xenos (= stranger, guest) and refers to the unusual male genitalia in this subgenus.

Species included in Psila (Xenopsila) subgen. n. Nearctic region: $P$. (X.) collaris Loew, 1869 comb. n., $P$. (X.) bivittata Loew, 1869 comb. n., P. (X.) lateralis Loew, 1860 comb. n. (transferred to Pseudopsila by Shewell, 1965); Palaearctic region (see Shatalkin, 1998b): P. (X.) arbustorum Shatalkin, 1986 comb. n. (originally described as a subspecies of nemoralis; elevated to species rank by Shatalkin, 1998b), $P .(X$.$) nemoralis$ Shatalkin, 1986 comb. n., $P$. (X.) tetrachaeta (Shatalkin, 1983) comb. n. (originally described in Chamaepsila; transferred to Pseudopsila by Shatalkin, 1986); Oriental region (see Frey, 1955; Shatalkin, 1998b): P. (X.) maculipennis (Frey, 1955) comb. n., P. (X.) nigricollis (Frey, 1955) comb. n., P. (X.) nigrohumera (Wang \& Yang, 1996) comb. n.

The generic placement of the west Palaearctic "Chyliza" gracilis Loew, 1854 needs to be re-examined. According to Shatalkin (1998b) this species probably belongs in "Pseudopsila". Psila maculadorsa (Wang \& Yang, 1996) from northern China might also be a Xenopsila. Psila (Freyopsila) nigrifulva (Shatalkin, 1983) was originally described in Pseudopsila but later transferred to Freyopsila (Shatalkin, 1986). Shatalkin (1998b) suspected that some Nearctic species currently placed in Psila s. str. might belong in "Pseudopsila", but all the species examined by us are placed correctly in Psila s. str. (not studied: $P$. atrata Melander, 1920, $P$. exigua van der Wulp, 1896, P. frontalis Coquillett, 1901).

\section{Key to the Nearctic species of the former subgenus "Pseudopsila" [= Psila (Xenopsila) plus P. (Psila) fallax-group]}

1 First flagellomere $1.5-2.1 \times$ as long as high (as in Fig. 4), and at least one of the following characters present: thorax (almost) completely black or yellow; two pairs of dorsocentrals; scutellum with two bristles.

............... Psila s. str. excl. fallax-group* First flagellomere $2.5-4.0 \times$ as long as high (Figs 1, 3, 5, 6), if shorter then with the following combination of characters: thorax bicoloured (yellow with black markings), one pair of dorsocentrals, scutellum with four bristles [Psila ("Pseudopsila")]............................. 2
2 Lateral portions of tergites 2-4 conspicuously bare, lacking marginal bristles. Male sternite 6 posteriorly emarginate, almost bipartite (Fig. 10). Phallus long (Fig. 12). Flight period in spring and early summer (late May to early July in Canada) $[$ Psila (Xenopsila) $] \ldots \ldots \ldots \ldots \ldots \ldots$

- Tergites 2-4 evenly haired or (in $P$. perpolita) laterally more or less extensively bare but some marginal bristles always present (often difficult to see in air-dried specimens). Male sternite 6 rectangular (Fig. 7). Phallus short (Fig. 9). Flight period from mid-summer to early fall (mid-July to late September in Canada) [Psila (Psila) fallax-group]. . . . 5

3 First flagellomere 2.0-2.1 $\times$ as long as high (Fig. 4). Ocellar triangle largely yellow, except for black ocellar tubercle and sometimes brownish median stripe in front of it (Fig. 2). [Occiput broadly yellow medially (Fig. 2). Yellow vitta of mesonotum reaching anterior margin; area around anterior thoracic spiracle narrowly yellow (Fig. 4). Four scutellar bristles, anterior pair small and hair-like, exceptionally absent. Wing membrane yellowish, often infuscated around veins $] \ldots \ldots \ldots \ldots \ldots \ldots \ldots \ldots \ldots \ldots \ldots \ldots$. $(X$.$) lateralis$ First flagellomere $2.5-2.6 \times$ as long as high (Figs 5, 6). Ocellar triangle dark to medium brown, without bright yellow areas. . . . . . . . . . . . . . . . 4

4 Two scutellar bristles. Yellow vitta of mesonotum reaching anterior margin, narrowed at level of postpronotal lobes; area around anterior thoracic spiracle brown (Fig. 5). Occiput brown, medially yellow. Wing membrane infuscated around veins, especially anteriorly (Fig. 13)........ $\ldots \ldots \ldots \ldots \ldots \ldots \ldots \ldots \ldots \ldots \ldots \ldots \ldots$. (X) bivittata

- Four scutellar bristles, anterior pair small and hair-like. Yellow vitta of mesonotum not reaching anterior margin; mesonotum largely brown between postpronotal lobes; area around anterior thoracic spiracle narrowly yellow (Fig. 6). Occiput brown. Wing membrane uniformly yellowish (Fig. 14) . . . . . . . . . . . . . . . . . . . P. (X.) collaris

5 Parafacials at narrowest point less than half as wide as vertical diameter of first flagellomere. First flagellomere $2.6-3.0 \times$ as long as high. Two subequal pairs of dorsocentral bristles (anterior pair exceptionally absent). Notopleural and postalar bristles weak, usually pale and scarcely distinguishable from surrounding hairs. Phallus without appendages. [Ocellar triangle black to brownish, anterior half sometimes yellowish brown; occiput brown. Yellow vitta of mesonotum not reaching anterior margin; mesonotum largely brown between postpronotal lobes $]. \ldots \ldots \ldots \ldots$. P. (P.) perpolita - Parafacials at least as wide as vertical diameter of first flagellomere. First flagellomere 3.6-4.0× as long as high. One (prescutellar) pair of dorsocentral bristles. Notopleural and postalar bristles strong and clearly differentiated from surrounding hairs, usually black. Phallus with a pair of small appendages (Fig. 9: ap). . . . . . . . . . . . . 6

6 Thorax entirely black. Ocellar triangle black to brown except for yellowish anterior half (Fig. 3); occiput mostly black. . . . . . . . . . . . . . . . . . . . . . P. (P.) fallax Thorax yellow except for black postpronotal lobes and upper pleuron (Fig. 1). Ocellar triangle yellow except for blackish ocellar tubercle (Fig. 1); occiput entirely yellow or with a pair of blackish spots behind vertical bristles....... P. (P.) angustata

\footnotetext{
* For a key to Nearctic Psila s. str. see Melander (1920).
} 


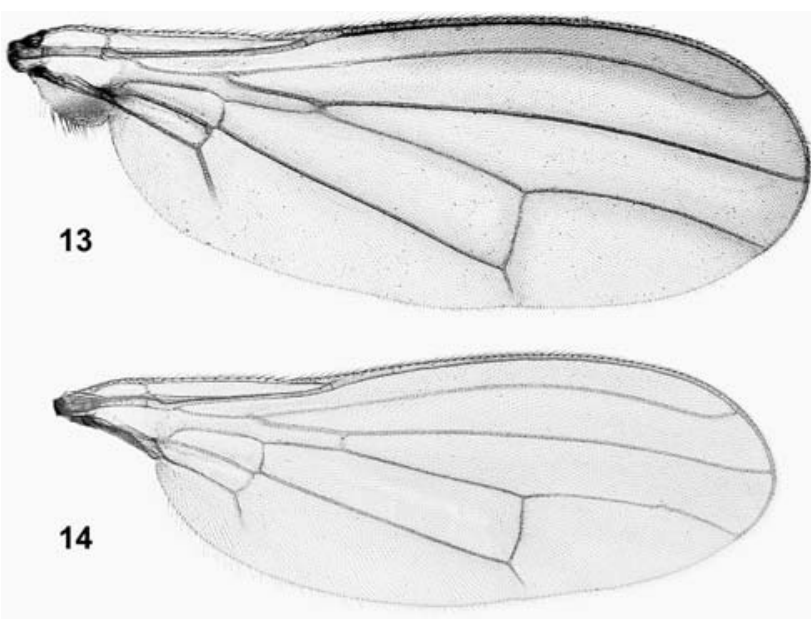

Figs 13-14. Wings of Psila (Xenopsila): $13-P$. (X.) bivittata (Canada, Quebec); $14-P .(X$.) collaris (Canada, Ontario).

\section{Species examined}

Psila (Xenopsila) bivittata Loew, 1869

(Figs 5, 13)

Psila bivittata Loew, 1869: 39.

Material examined. Canada, Ontario: $3 \hat{\sigma}, 6 \%$, Orton, Orwell, Windsor. Quebec: $1 \uparrow$, Old Chelsea (all DEBU).

\section{Psila (Xenopsila) collaris Loew, 1869}

(Figs 6, 10, 14)

Psila collaris Loew, 1869: 39.

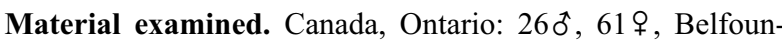
tain, Brantford, Delhi-Simcoe Railway, Dorset Hill, Hilton Township, Inverhuron Provincial Park, Killbear Provincial Park, Lake Kahshe $5 \mathrm{~km}$ S Gravenhurst, Manestar Tract and Wilson Tract NNW St. Williams, 7 km W Mattawa, Norway Lake, 4.7 km W Pancake Bay Provincial Park, Point Pelee, Port Franks, Rondeau Provincial Park, Sleeping Giant Provincial Park, Thessalon, Wainfleet Bog $8 \mathrm{~km} \mathrm{~S}$ Welland, Windsor. Quebec: 1 \% Old Chelsea. New Brunswick: $8 \%$, St. Andrews. USA, Michigan: $10,1 \mathrm{~km}$ E Ogden Dunes. New York: 1 \% , Claverack (all DEBU).

\section{Psila (Xenopsila) lateralis Loew, 1860}

(Figs 2, 4, 11, 12)

Psila lateralis Loew, 1860: 81.

Psila colorata Melander, 1920: 95 (synonymy by Shewell, 1965: 640)

Material examined. Canada, Ontario: $1 \delta^{\hat{\alpha}}, 4 \%$, Pinery Provincial Park, Port Franks. USA, Texas: $10,10 \%$, College Station. Virginia: 10 , Montgomery Co., Pandapas Pond; 1 , , Giles Co., Ripplemead. South Carolina: 1\%, Georgetown Co., Hobcaw Barony, Belle Baruch Marine Field Station (all DEBU).

\section{PHYLOGENY}

Previous views on the relationships of Xenopsila. The problem of the phylogenetic relationships of Xenopsila is of great significance in the context of the phylogeny of the subfamily Psilinae. While most authors treated Xenopsila (= Pseudopsila auctt.) simply as a subordinate group of Psila s. 1., Shatalkin (1998b) tentatively placed Xenop-

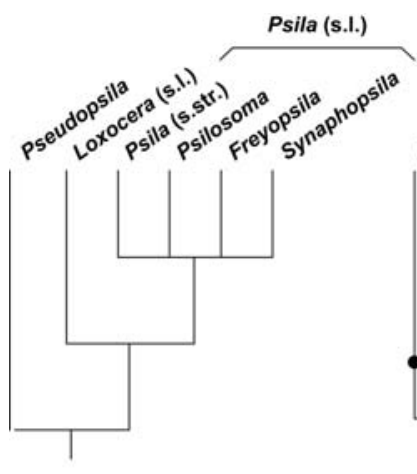

Shatalkin $(1989,1998 b)$

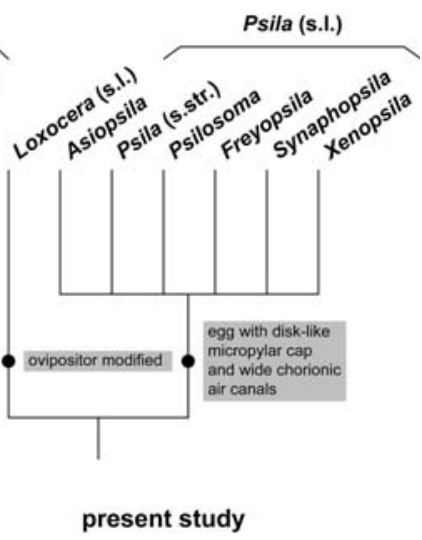

Fig. 15. Phylogeny of the subfamily Psilinae. Explanations: Black circles represent apomorphic character states. Xenopsila $=$ Pseudopsila sensu Shatalkin (nec Johnson, 1920). Asiopsila was transferred from Loxocera to Psila s. 1. by Buck \& Marshall (2006). For the subgeneric classification of Loxocera see Buck $\&$ Marshall (2006).

sila at the base of the subfamily (i.e. as the sister group of Psila s. 1. + Loxocera s. 1.), considering it "the most primitive element within Psilinae". In Fig. 15 we translate Shatalkin's (1. c.) written hypothesis into a cladogram. His removal of Xenopsila from Psila s. 1. was based on the absence of certain male genitalic characters, which he considered apomorphic for Psila s. 1. However, no evidence for a monophyletic Psila s. 1. + Loxocera s. 1. as the sister group of Xenopsila was presented. As shown below, the character polarizations that led Shatalkin to the removal of Xenopsila from Psila s. 1. are based on wrong homology assumptions.

\section{Adult morphology}

Homologies and character polarities of the male genitalia. The first apomorphic character that Shatalkin (1998b) mentioned for Psila is the so-called "dorsally divided hypandrium". This term refers to the condition described above for Psila s. str. (see Diagnosis), where the hypandrial arms [= "gonopod derivatives" sensu Shatalkin; see Buck \& Marshall, 2006] are separated at their base from the hypandrial plate [= "hypandrium" sensu Shatalkin]. Shatalkin does not discuss the distribution of this character state in Psilinae but appears to imply its presence in the whole genus Psila s. 1., for which it would consequently have to be considered a defining character. According to Shatalkin (1998b) the plesiomorphic condition is found in Xenopsila, where hypandrial arms and hypandrial plate supposedly form a single sclerite. Unfortunately, Shatalkin mistook the phallapodemic sclerite for the hypandrial plate, and the hypandrial arms are in fact fused to the former while the latter has been lost. The true homology of the phallapodemic sclerite is revealed by the fact that it supports the phallus at its posterior extreme.

The second character used in Shatalkin's (1998b) discussion of the phylogeny of the Psilinae is the insertion of the postgonites on the phallapodemic arms. According to Shatalkin (1. c.) an apical insertion (as shown by Psila s. 
str.) is considered apomorphic while a more basal (anterior) insertion (as shown by Xenopsila) is considered plesiomorphic. Even if Shatalkin's polarization was true the position of the postgonites cannot justify the removal of Xenopsila from Psila s. 1. because the supposedly plesiomorphic state also occurs in the subgenera Freyopsila and Synaphopsila Hendel, 1934 (Shatalkin, 1986, 1998b). Shatalkin's wrong polarization results from the assumption that the postgonites of Psilinae are not in fact postgonites (which are usually inserted apically) but secondary structures that were derived from ventral appendages of the phallapodemic sclerite. According to Shatalkin (1998b) such ventral appendages occur in certain species of Chyliza Fallén, 1820. We consider this "pseudopostgonite" hypothesis highly unlikely because outgroup comparison (with Belobackenbardiinae, and related Diopsoidea families) suggests that postgonites are part of the ground plan of Psilidae. The only psilid taxa that lack postgonites are Psila (Asiopsila) and perhaps some Chyliza (fide Shatalkin, 1998, but see below). If postgonites were absent in the groundplan of Psilinae + Chylizinae then secondary, postgonite-like structures must have developed three times independently within the family (within Chyliza, in Loxocera s. 1., and within Psila s. 1.). This scenario is less parsimonious than the assumption of an independent loss in Asiopsila and some Chyliza. Furthermore, Shatalkin's reiterated claim that postgonites are missing in all Chyliza species excluding the Ch. cylindrica-group (Shatalkin, 1998a, b, 2002) is neither confirmed by other authors' findings nor by our own observations. Verbeke $(1952,1963)$ describes and illustrates postgonites for many African species, Steyskal (1987) does so for the Nearctic Ch. apicalis Loew, 1860, and Albuquerque (1957) illustrates postgonites in several Neotropical species (without labelling them in his figures). Our own observations confirm the presence of postgonites in all species available to us, including several species from the Nearctic and Neotropical regions and one species from Russia. Considering that the postgonites of many Chyliza species are small and closely associated with the phallus it seems possible that they were overlooked or mistaken as part of the phallus by Shatalkin.

\section{Egg morphology}

Further evidence for the position of Xenopsila as a subgenus of Psila s. 1. comes from egg morphology. Egg morphology has not previously been used in the phylogenetic reconstruction of the Psilidae but has also proven very useful in Diopsidae (Meier \& Hilger, 2000), a related family belonging in the same superfamily Diopsoidea as the Psilidae. Egg characters also helped to reveal the true affinities of Asiopsila (see Buck \& Marshall, 2006, and Discussion).

Below we describe the eggs of Psila (Xenopsila) lateralis and Chyliza notata Loew, 1869, each representing the first detailed published description of an egg in their respective taxon. The only available description in Chyliza, pertaining to the Neotropical Ch. consanguinea Schiner, 1858 (Albuquerque, 1957), is extremely sche-

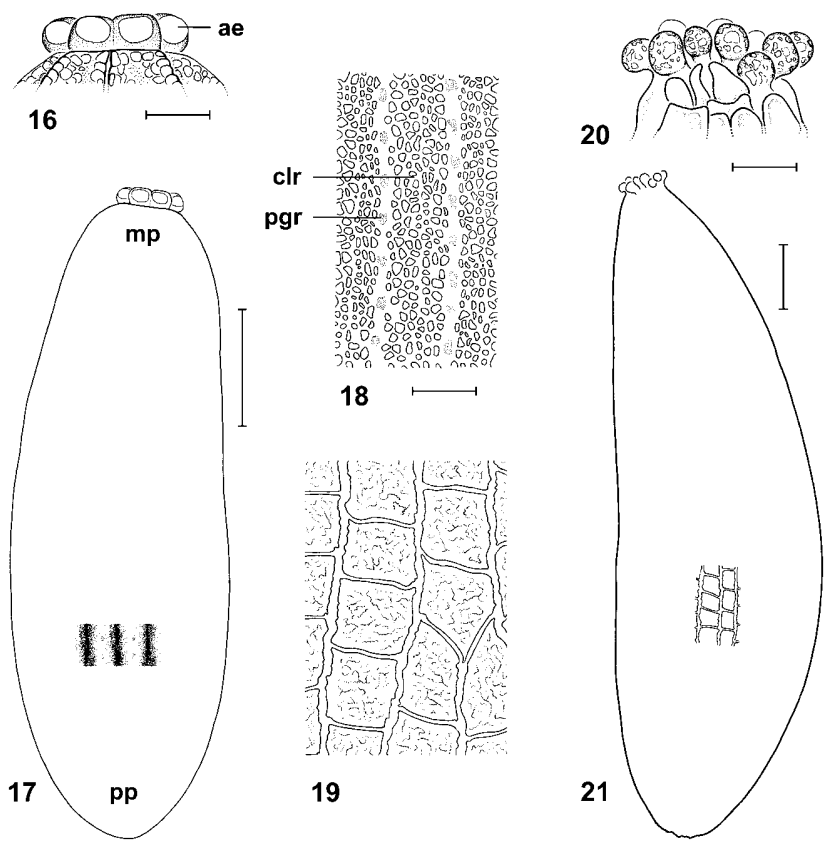

Figs 16-21. Eggs of Psilidae. Psila (Xenopsila) lateralis (Canada, Ontario): 16 - micropylar cap, lateral view; 17 - egg, lateral view; 18 - chorion, lateral surface, fine structure. Chyliza notata (USA, Virginia): 19 - chorion, lateral surface, fine structure; 20 - micropylar cap, lateral view; 21 - egg, lateral view. Scale $0.1 \mathrm{~mm}$ (egg, total) and $0.025 \mathrm{~mm}$ (others). ae - aeropyle, $\mathrm{clr}$ - longitudinal ridge of chorion, pgr - patch of granular texture, $\mathrm{mp}$ - micropylar pole, $\mathrm{pp}$ - posterior pole.

matic and does not provide any details of phylogenetic relevance (e.g., morphology of micropylar area, chorionic surface structure). The egg of Chyliza (the only genus in Chylizinae) is of interest because this group is the putative sister group of the Psilinae (Shatalkin, 2002). Eggs of the recently described subfamily Belobackenbardiinae (with the single genus Belobackenbardia Shatalkin, 2002) are unknown, and the relationships of this group with the remainder of the Psilidae remain obscure (Shatalkin, 2002).

\section{Psila (Xenopsila) lateralis Loew, 1860}

(Figs 16-18)

Description. Egg elliptical (Fig. 17), length ca. 0.56 $\mathrm{mm}$, width ca. $0.18 \mathrm{~mm}$ (i.e., about $0.7 \times$ as long as abdominal segments 3 and 4 combined). Micropylar pole with small, circular, disk-like elevation, posterior pole rounded. Egg surface in mid section with ca. 18 broad, longitudinal, rounded ridges around its circumference. Ridges approximately semicircular in cross section, not connected by narrower transverse ridges. Number of longitudinal ridges decreasing towards each pole through anastomoses, at base of micropylar cap equalling number of aeropyles on micropylar elevation; each ridge terminating at an interspace between base of two aeropyles. Longitudinal ridges with irregular reticulation (Fig. 18, reticulation located on inner surface of chorionic air canals; see Hinton, 1981: Plate 123 E, F). Grooves between ridges unreticulated, with small patches of more 
granular texture placed at regular intervals (Fig. 18: pgr) These patches might represent plastronic surfaces, which have also been reported from eggs of Loxocera aristata (Panzer, 1801) (Gaponov, 1999) and many other brachyceran eggs (Hinton, 1981: e.g. Plate $139 \mathrm{C}-\mathrm{E}$ ). Micropylar elevation flat, bearing nine large, circular aeropyles around circumference (Fig. 16: ae). Micropyle tiny, located exactly in centre of disk-like process. Posterior pole without specialized structures, bearing same reticulation as on longitudinal ridges.

Material examined. Canada: Ontario, 1 egg from one female, Lambton Co., Port Franks, Watson Property nr. L-Lake, 20.-26.vi.1996, pans, J. Skevington (DEBU).

\section{Chyliza notata Loew, 1869}

(Figs 19-21)

Description. Egg as in Fig. 21; length 1.03-1.07 mm, width ca. $0.25 \mathrm{~mm}$ (i.e., about $0.8 \times$ as long as abdominal segments 3-4 combined). Micropylar pole narrowly truncate, posterior pole rounded. Surface (Fig. 20) covered by broadly separated, prominent, linear, longitudinal ridges that are connected at regular intervals by much less elevated transverse ridges, thus dividing surface into approximately square areas. Ridges lamellate, parallelsided in cross-section, longitudinal ones about $3 \mathrm{x}$ as high as transverse ones and slightly thickened at intersections. Number of ridges in mid section totalling about 26 across circumference. Chorion between ridges with a pattern of short, sinuous, punctate lines. Surface structure at posterior pole not substantially different from general surface, ridges more irregular and somewhat thickened. Micropylar area surrounded by a circle of 11-14 small, slightly clubbed, apparently solid processes (Fig. 19). Micropyle at bottom of small pit, edges of pit coarsely granulose, micropylar area otherwise almost plain.

Material examined. USA: Virginia, ten eggs from one female, Shenandoah Natl. Pk., mi. 65-100, 29.v.1979, sweeps, M.J. Sharkey (DEBU).

\section{Discussion of morphology}

Eggs of only five species in two subgenera of Psila s. 1. have previously been described: P. (Psila) hennigi (Ashby \& Wright, 1946; Hinton, 1981; Meier \& Hilger, 2000; as P. rosae), P. (Psila) rufa Meigen, 1826, P. (Psila) fimetaria (both Gaponov, 1999), P. (Psila) merdaria Collin, 1944 (Meier \& Hilger, 2000) and $P$. (Asiopsila) decorata (de Meijere, 1914) (Buck \& Marshall, 2006). The egg of Psila (Xenopsila) lateralis is very similar to these species, but the chorion lacks the short, transverse ridges that connect the longitudinal ridges in other species (e.g., Buck \& Marshall, 2006: Fig. 92: ctr). All described Psila eggs appear to be characterized by a sessile, disk-like, circular elevation at the micropylar pole ("micropylar cap"), although Ashby \& Wright's (1946) line drawings show a stalked micropylar elevation for $P$. hennigi, thus differing markedly from Hinton's (1981) and Meier \& Hilger's (2000) SEM micrographs of the same species.

All known Psila eggs differ radically from eggs of its sister genus Loxocera (see Buck \& Marshall, 2006). In
Loxocera the micropylar pole is simple, more or less tapered, and does not possess a distinct cap with regularly placed, large aeropyles that are perpendicularly oriented to the long axis of the egg. Furthermore, the chorionic respiratory system of Loxocera does not possess wide longitudinal air canals that could be observed under a compound microscope. The distinctive micropylar cap and wide, longitudinal air canals are also absent from the next outgroup taxon Chyliza. The micropylar cap of Psila must therefore be considered apomorphic and appears to be unique in Schizophora flies. Wide air canals associated with coarse longitudinal ridging of the chorion surface are probably widespread in Schizophora, and can also be found in many species of the related family Diopsidae (Meier \& Hilger, 2000). Based on its distribution within Psilidae we tentatively consider this character state autapomorphic for Psila, pending future study of the eggs of Belobackenbardia.

Superficially, the micropylar corona of the egg of $C h$. apicalis bears some resemblance to the micropylar cap of Psila. However, a closer examination reveals significant morphological differences: The coronal processes of Chyliza are solid (lacking wide air canals that terminate in an aeropyle), they are free (not coalesced to a single disk), and they are continuous with the remainder of the egg (not delimited from it by suture at their base). Unlike Psila, the micropyle is not situated on a flat surface but lies in a deep depression surrounded by the corona. The modifications of the micropylar pole are probably autapomorphic for Chyliza as well as the structure of the chorionic surface (with thin, elevated, lamellar ridges).

\section{Phylogenetic relevance for the classification of Psila}

The unique egg apomorphies of Psila s. str., Xenopsila, and Asiopsila are probably representative of the whole genus Psila s. 1. as defined by Shatalkin (1986, 1989, 2002) and Iwasa (1998) (Fig. 15). Eggs of several subgenera of Psila have not yet been examined (i.e., Psilosoma Zetterstedt, 1860, Freyopsila, Synaphopsila and Afropsila Shatalkin, 2002), but most or all probably belong in Psila s. 1. Unlike all other subgenera, females of Psilosoma possess a specialized ovipositor similar to Loxocera. The examination of Psilosoma eggs will therefore establish whether egg morphology is linked to ovipositor morphology. Outside Psila s. 1., eggs of Tropeopsila Shatalkin, 1983 should also be examined in order to confirm its current placement as a subgenus of Loxocera.

\section{DISCUSSION}

Redefinition of Psila s. l. Based on egg morphology and male genitalic characters we propose a slightly revised definition of the genus Psila. According to Shatalkin $(1986,1989,2002)$ and Iwasa (1998) the genus consists of the following six subgenera: Afropsila, Freyopsila, Pseudopsila auctt. (=Xenopsila subgen. n.), Psila s. str., Psilosoma, and Synaphopsila. The only putative synapomorphy for this clade mentioned in previous literature is the "divided hypandrium" (hypandrial arms separate from hypandrial plate, Shatalkin, 1998b). However, certain groups and species within Psila s. 1. do not pos- 
sess a divided hypandrium. According to Shatalkin's (1986) figures the hypandrial arms seem to be fused to the hypandrial plate in Freyopsila, and a connection between both definitely exists in at least one species of Psilosoma (see below) and in Psila (P.) perpolita (see above). At least in the latter the fused condition almost certainly represents a character reversal. Further study is necessary in the other cases in order to determine which hypandrial configuration is plesiomorphic. Considering the uncertain polarity of the hypandrial character we propose the modified micropylar cap as a new defining character for Psila s. 1. This slightly expands the taxonomic boundaries of the genus by also including Asiopsila (whose species possess an "undivided" hypandrium).

Evolutionary trends of Psilinae genitalia. Within the Psilinae the hypandrial complex undergoes various modifications, which can be summarized as follows: Based on outgroup comparison with the Chylizinae and Belobackenbardiinae an "undivided hypandrium" is part of the Psilinae ground plan. Primitively, the hypandrial plate forms a relatively narrow, transverse bar connecting the hypandrial arms anteriorly. This condition is present in Chyliza (e.g., Steyskal, 1987: Fig. 7), many species of Loxocera (Imantimyia Frey, 1925) (e.g., Buck \& Marshall, 2006: Fig. 22) and Asiopsila. Various evolutionary trends can be observed in the genus Psila: While the hypandrial plate becomes enlarged in many species of Psila s. str. (e.g., Fig. 9; part of ground plan?) it is totally reduced in the subgenera Xenopsila and Afropsila (see Shatalkin, 2002). The plesiomorphic primary connection between the hypandrial arms and the hypandrial plate is retained in Asiopsila (Shatalkin, 1998b: Fig. 6) and Psilosoma sp. (1 $\delta$, Czechoslovakia, DEBU; character reversal?) but apparently not in $P$. audouini (Zetterstedt, 1835) (Shatalkin, 1986: Fig. 4). In Psila s. str. (e.g., Fig. 9; few exceptions) and Synaphopsila (Shatalkin, 1986: Fig. 6) the hypandrial arms are disconnected from the hypandrial plate but are still closely associated with it. In groups that have lost the hypandrial plate the hypandrial arms are either free as in Afropsila (Shatalkin, 2002: Figs $9,10)$, or secondarily fused to the phallapodemic sclerite as in Xenopsila. Outside Psila s. 1., a reduction of the hypandrial plate associated with a fusion of the hypandrial arms to the phallapodemic sclerite has occurred convergently in Loxocera s. str. (Buck \& Marshall, 2006).

Relationships of Xenopsila. The absence of a hypandrial plate, the secondary fusion of the hypandrial arms with the phallapodemic sclerite and the basal position of the postgonites is apomorphic with regard to the ground plan of Psila s. 1., and characterizes Xenopsila as a derived clade within this genus. The intrageneric relationships of Xenopsila cannot be determined without undertaking a badly needed subgeneric revision of Psila, which is well beyond the scope of this paper. However, certain apomorphic characters of the male genitalia that are shared with other subgenera provide clues about the possible sister group: Both elongate phalli and anteriorly displaced postgonites occur in the eastern Palaearctic/ Oriental subgenera Freyopsila and Synaphopsila (Iwasa,
1991, 1994; Shatalkin, 1986). The monophyly of Freyopsila is reasonably well established by a conspicuously sclerotized and capsule-like basiphallus (Shatalkin, 1986), the monophyly of Synaphopsila by a very peculiar hypandrial bridge (1. c.: Fig. 6, mislabelled as "surstylar apodeme") and the lack of dorsocentral bristles (Shatalkin, 1986). Both subgenera lack postvertical bristles, hinting the possibility of a sister group relationship between these two taxa. Long phalli also occur in Psilosoma but this subgenus shows a more primitive hypandrial configuration (see above) and is probably not closely related. Another character, the loss of the hypandrial plate is shared with the Afrotropical genus Afropsila (Shatalkin, 2002), but this is probably due to convergence.

ACKNOWLEDGEMENTS. We thank M. Kotrba (ZSMC), J.M. Cumming and J. Skevington (CNCI) for loaning material under their care. The line drawings were skilfully executed by $\mathrm{M}$. Musial. This study was funded by NSERC (Natural Sciences and Engineering Research Council of Canada) through different grants to S.A. Marshall.

\section{REFERENCES}

Albuquerque D. De O. 1957: Fauna do Distrito Federal. XXXVII - Redescrição de Chyliza consanguinea Schiner, 1858 e descrição de duas espécies novas (Diptera - Psilidae). Bolm Mus. Nac. Rio de J. (N. S., Zool.) 162: 1-11.

Andersson H. 1977: Taxonomic and phylogenetic studies on Chloropidae (Diptera) with special reference to Old World genera. Entomol. Scand. (Suppl.) 8: 200 pp.

Ashby D.G. \& Wright D.W. 1946: The immature stages of the carrot fly. Trans. R. Entomol. Soc. Lond. 97: 355-379.

Buck M. \& Marshall S.A. 2006: Revision of New World Loxocera (Diptera, Psilidae), with phylogenetic redefinition of Holarctic subgenera and species groups. Eur. J. Entomol. 103: 193-219.

CAPELle K.J. 1953: A revision of the genus Loxocera in North America with a study of geographical variation in L. cylindrica. Ann. Entomol. Soc. Am. 46: 99-114.

Cogan B.H. 1977: Family Psilidae. In Delfinado M.D. \& Hardy D.E. (eds): A Catalog of the Diptera of the Oriental Region. Vol. 3: Suborder Cyclorrhapha (Excluding Division Aschiza). The University Press of Hawaii, Honolulu, pp. 24-27.

Cresson E.T. 1919: Dipterological notes and descriptions. Proc. Acad. Nat. Sci. Philad. 71: 171-194.

FABRICIUS J.C. 1794: Entomologia systematica emendata et aucta. Secundum classes, ordines, genera, species adjectis synonymis, locis, observationibus, descriptionibus. Vol. 4. Copenhagen, $472 \mathrm{pp}$.

FreY R. 1925: Zur Systematik der paläarktischen Psiliden (Dipt.). Notul. Entomol. 5: 47-50.

Frey R. 1955: Studien über ostasiatische Dipteren V. Psilidae, Megamerinidae. Notul. Entomol. 35: 122-137.

GAPONOV S.A. 1999: Ultrastructure of egg exochorion in the family Psilidae (Diptera). Zool. Zh. 78: 755-758 (in Russian, English abstr.)

Hadley A. 2004: CombineZ version 4.6. http://www.microscopy-uk.org.uk/index.html.

HagenBaCh J.J. 1822: Symbola Faunae Insectorum Helvetiae. Fasc. 1. Basel, 48 pp.

Hendel F. 1917: Beiträge zur Kenntnis der acalyptraten Musciden. Dt. Entomol. Z. 1917: 33-47.

Hinton H.E. 1981: Biology of Insect Eggs. Vols 1-3. Pergamon Press, Oxford, xxiv +1125 pp. 
Iwasa M. 1991: Taxonomic study of the genus Psila Meigen (Diptera, Psilidae) from Japan, Sakhalin and the Kurile Islands. Jap. J. Entomol. 60: 229-237.

IwASA M. 1994: Five new species of the genus Psila Meigen (Diptera, Psilidae) from Nepal. Jap. J. Entomol. 62: 693-700.

Iwasa M. 1998: 3.11. Family Psilidae. In Papp L. \& Darvas B. (eds): Contributions to a Manual of Palaearctic Diptera (With Special Reference to Flies of Economic Importance). Vol. 3: Higher Brachycera. Science Herald, Budapest, pp. 177-183.

Johnson C.W. 1920: A revision of the species of the genus Loxocera, with a description of a new allied genus and a new species. Psyche (Camb.) 27: 15-19.

Latreille P.A. 1829: Les Crustacés, les Arachnides et les Insectes. In Cuvier G.C.L.D. (ed.): Le Règne Animal Distribué d'après son Organisation, pour Servir de Base à l'Histoire Naturelle des Animaux, et d'Introduction à l'Anatomie Comparée. Vol. 5(2). 2nd ed. Paris, 556 pp.

Linnaeus C. 1761: Fauna Svecica Sistens Animalia Sveciae Regni. Stockholm, 578 pp.

Loew H. 1856: Neue Beiträge zur Kenntnis der Dipteren. Vierter Beitrag. Programm K. Realschule Meseritz 1856: $1-57$.

Loew H. 1860: Diptera americana ab Osten-Sackenio collecta. Decas prima. Wien. Entomol. Mschr. 4: 79-84.

Loew H. 1869: Diptera Americae septentrionalis indigena. Berl. Entomol. Z. 13: 1-52, 129-186.

McAlpine J.F. 1981: Morphology and terminology - adults. In McAlpine J.F., Peterson B.V., Shewell G.E., Teskey H.J., Vockeroth J.R. \& Wood D.M. (eds): Manual of Nearctic Diptera. Vol. 1. Research Branch, Agriculture Canada, Monograph 27, Ottawa, pp. 9-63.

Meigen J.W. 1803: Versuch einer neuen GattungsEintheilung der europäischen zweiflügligen Insekten. Magazin Insektenk. 2: $259-281$.

Meier R. \& Hilger S. 2000: On the egg morphology and phylogenetic relationships of Diopsidae (Diptera: Schizophora). $J$. Zool. Syst. Evol. Res. 38: 1-36.

Melander A.L. 1920: Synopsis of the dipterous family Psilidae. Psyche (Camb.) 27: 91-101.

Robineau-Desvoidy J.B. 1830: Essai sur les Myodaires. Inst. France, Cl. Sci. Math. Phys., Acad. R. Sci., Mém. pésentés par divers Savants (Sér. 2) 2: 1-813.
Shatalkin A.I. 1983: New species of flies of the family Psilidae (Diptera) from the Far East. Entomol. Obozr. 62: 360-366 (in Russian; English translation in Entomol. Rev., Wash. 62: 127-134).

Shatalkin A.I. 1986: Review of the eastpalaearctic flies of Psila Mg. (Diptera, Psilidae), with the key of the Palaearctic species. Proc. Zool. Inst., Leningrad 146: 23-43 (in Russian, English abstr.).

Shatalkin A.I. 1989: Notes on the Palaearctic Psilidae (Diptera). Archs Zool. Mus. Moscow State Univ. 27: 88-113 (in Russian, English abstr.).

Shatalkin A.I. 1998a: Review of the Asian species of Chyliza Fallén (Diptera, Psilidae). Russ. Entomol. J. 6(1-2)[1997]: 89-111.

Shatalkin A.I. 1998b: Asian species of Loxocera Meigen (Diptera: Psilidae). Russ. Entomol. J. 6(3-4)[1997]: 87-97.

Shatalkin A.I. 2002: Afrotropical Psilidae (Diptera). 1. Genera Belobackenbardia gen. n. and Psila Meigen, 1803. Russ. Entomol. J. 10[2001]: 417-424.

Shewell G.E. 1965: Family Psilidae. In Stone A., Sabrosky C.W., Wirth W.W., Foote R.H. \& Coulson J.R. (eds): A Catalog of the Diptera of America North of Mexico. United States Department of Agriculture, Washington, D.C., pp. 638-641

SteysKal G.C. 1987: 60. Psilidae. In McAlpine J.F., Peterson B.V., Shewell G.E., Teskey H.J., Vockeroth J.R. \& Wood D.M. (eds): Manual of Nearctic Diptera. Vol. 2. Research Branch, Agriculture Canada, Monograph 28, Ottawa, pp. 781-784.

Thompson F.C. \& Pont A.C. 1994 [1993]: Systematic Database of Musca Names (Diptera). Theses Zoologicae Vol. 20. Koeltz Scientific Books, Königstein, Germany, ii + 219 pp.

Verbeke J. 1952: Psilidae (Diptera Cyclorrhapha). Explor. Parc Natn Albert, Miss. G.F. de Witte, 1933-1935, 78: 64 pp.

Verbere J. 1963: Notes sur quelques Psilidae et Micropezidae éthiopiens et malgaches (Diptera, Acalyptera). Rev. Zool. Bot. Afr. 67: 163-175.

Westwood J.O. 1840: An Introduction to the Modern Classification of Insects. Synopsis of the Genera of British Insects. London, $158 \mathrm{pp}$.

Received March 23, 2005; revised and accepted September 16, 2005 